\title{
Establishment and persistence of species-rich patches in a species-poor landscape: role of a structure-forming subtidal barnacle
}

\author{
A. R. Davis* ${ }^{*}$ D. W. Ward \\ Institute for Conservation Biology and School of Biological Sciences, University of Wollongong, \\ New South Wales 2522, Australia
}

\begin{abstract}
Some sessile invertebrates are capable of maintaining space in barren habitats produced by sea urchins, thereby creating species-rich patches in a species-poor landscape. We sought to determine the role of a large and common barnacle, Austrobalanus imperator, in the establishment and persistence of these species-rich patches. Barnacle density was modified in 2 experiments at sites in southeastern Australia. The first experiment concerned community establishment and involved the addition of barnacles in 4 densities (zero [control], low, medium and high) to plots on vertical rock surfaces. The addition of barnacles at ecologically realistic densities and spatial arrangements rapidly resulted in statistically significant increases in invertebrate cover and diversity. After 56 mo, the diversity of invertebrates was significantly higher on plots that received high densities of barnacles relative to controls. However, invertebrate cover no longer differed between treatment plots, despite evidence that barnacles modify the grazing intensity of sea urchins. The second experiment assessed the persistence of sessile invertebrates following the removal of barnacles from wellestablished assemblages dominated by sponges. The removal of barnacles did not hinder the rapid recovery of sponges to pre-manipulation levels, indicating that barnacles played an inconsequential role in well-established assemblages. We conclude that barnacles play an important functional role in this system, as they promote the recruitment of sessile invertebrates. It was also clear that the development of invertebrate assemblages on natural vertical surfaces was very slow, which raises the question of whether we are examining these important occupiers of space at appropriate temporal and spatial scales.
\end{abstract}

KEY WORDS: Cirripedia $\cdot$ Echinoidea $\cdot$ Grazing activity $\cdot$ Habitat structure $\cdot$ Porifera $\cdot$ Sessile invertebrates $\cdot$ Structural heterogeneity $\cdot$ Rocky subtidal zone

\section{INTRODUCTION}

The importance of heterogeneous environments for the structure and dynamics of plant and animal assemblages is well established (Bell et al. 1991, Kosala \& Pickett 1991). As argued by McCoy \& Bell (1991), progress in this area has been mired in confused terminology; nevertheless, there appears to be general agreement that habitat heterogeneity involves at least 2 components. The first is patchiness in habitat types across a landscape, and the second is the finer-scale complexity associated with the physical or architectural nature of the substratum and associated biota (Addicott et al. 1987, McCoy \& Bell 1991). Here, we follow the terminology of Sebens (1991) and refer to complexity associated with the substratum as habitat structure.

In a variety of assemblages, habitat structure has been shown to exert an important influence at all levels of biological organization. At the level of the individual, it may modify the risk of predation (Heck \& Orth 1983, Jeffries \& Lawton 1984, Kerfoot \& Sih 1987), 
while it may also influence the structure and dynamics of assemblages (Lawton 1983, Downing 1986, Williamson \& Lawton 1991). For sessile benthic invertebrates the nature of the substratum, such as surface rugosity, can be an important determinant of patterns of settlement and post-settlement survivorship (Dean \& Hurd 1980, Dean 1981, Keough \& Downes 1982, Sebens 1991, Walters \& Wethey 1991, Walters 1992, Guichard \& Bourget 1998). Superimposed on these patterns is the biogenic structure imparted by the biota, which may modify patterns of settlement and survivorship, often via the creation of refugia (Russ 1980, Witman 1985, Littler et al. 1986, Davis 1987, 1996) or by changing hydrodynamic conditions (Eckman 1983, Littler et al. 1983, Walters et al. 1999).

The impact of sea urchins on the distribution and abundance of macroalgae is well established in subtidal community ecology (Lawrence 1975). The grazing activities of urchins may also modify patterns of sessile invertebrate distribution and abundance (Vance 1979, Ayling 1981, Himmelman et al. 1983, Sebens 1985), although it is now clear that many sessile invertebrates defend themselves chemically, physically, or both (e.g. Hill et al. 2005). In addition, biological disturbance associated with urchin grazing may play an indirect role in shaping patterns in the shallow subtidal zone. Both macroalgae and sessile invertebrates require space, which is frequently a limiting resource in shallow-water assemblages. Hence, interactions between algae and invertebrates may be characterized by preemption, overgrowth and interference competition (Connell 1961, Dayton 1975, Underwood et al. 1983). Urchin grazing may act to mediate interactions between algae and invertebrates, as has been demonstrated for tropical and temperate locations (Sammarco 1980, Coyer et al. 1993).

In temperate Australian waters, the most conspicuous subtidal grazer is the diadematid sea urchin Centrostephanus rodgersii (Agassiz, 1863). This urchin creates and maintains areas devoid of fleshy and foliose macroalgae that are dominated by grazerresistant crustose algae, the so-called urchin-grazed barrens (Fletcher 1987). Unlike many temperate echinoids, this urchin is strongly reliant on shelter, spending the day in crevices, then emerging at night to forage (Andrew 1993). In these barrens, a low cover of sessile invertebrates manages to maintain space despite the often intense urchin grazing (Wright et al. 1997, Davis et al. 2003). Sponges, ascidians and bryozoans are particularly evident on vertical surfaces, usually in association with the large balanoid barnacle Austrobalanus imperator (Darwin, 1854; hereafter Austrobalanus). This barnacle often grows to $2.5 \mathrm{~cm}$ in height with a basal diameter of up to $4 \mathrm{~cm}$; it regularly achieves densities $>50$ ind. $0.25 \mathrm{~m}^{-2}$ on vertical sur- faces (Davis \& Ward 1999). A positive correlation between the cover of sessile invertebrates and the number of Austrobalanus for 3 locations in southeastern Australia has been reported (Davis \& Ward 1999). Here, we used experiments to explore the role of this barnacle in the establishment and persistence of sessile invertebrate assemblages. We reasoned that high densities of this large barnacle would interfere with the grazing activities of the urchins, thereby creating refugia that allow sessile invertebrates to become established and persist. Refugia may play an important role in structuring assemblages (Menge \& Lubchenco 1981). Indeed, Creese (1982) reported that high barnacle densities interfere with the grazing activities of limpets. In contrast to many regions of the world where mussels contribute to the biogenic complexity of the substratum and thus provide a refuge for a variety of fauna and flora (Witman 1985), mussels are not a common feature of the sublittoral zone in southeastern Australia.

The present study examined 3 predictions about the functional importance of the barnacle Austrobalanus: first, that the presence of Austrobalanus facilitates the establishment of invertebrates; second, that Austrobalanus does this by creating a refuge from urchin grazing; and third, that, once established, the invertebrates are able to maintain space when the barnacles are removed. Previous work has demonstrated that sponges commonly found in urchin-grazed barrens are chemically and physically defended against grazing (Wright et al. 1997, Ferguson \& Davis 2008) and it follows that they should be able to maintain space if faced with elevated grazing intensity. We tested these predictions by experimentally manipulating barnacle densities and by recording species richness and invertebrate cover in experimental plots for up to $56 \mathrm{mo}$.

\section{MATERIALS AND METHODS}

Study locations. Experiments were done on coastal reefs and adjacent islands near Wollongong, New South Wales, Australia ( $\left.34^{\circ} 27.3^{\prime} \mathrm{S}, 150^{\circ} 55.7^{\prime} \mathrm{E}\right)$ and on subtidal rocky reefs at the entrance to Jervis Bay $\left(35^{\circ} 4.5^{\prime} \mathrm{S}, 150^{\circ} 47^{\prime} \mathrm{E}\right), \sim 100 \mathrm{~km}$ to the south (see Fig. 2 in Davis \& Ward 1999). Experimental plots at these sites were established in 10 to $12 \mathrm{~m}$ of water on the vertical surfaces provided by rock walls or the sides of large boulders. All study plots were established in the urchin-grazed barrens and showed evidence of intense grazing. Urchin densities in nearby crevices were extremely high (usually averaging $>2 \mathrm{~kg} \mathrm{~m}^{-2}$ wet weight; Davis et al. 2003). The cover of grazer-resistant crustose coralline algae on the vertical surfaces usually averaged $>80 \%$, with sessile invertebrates accounting 
for the remaining $20 \%$ cover (Davis et al. 2003). Sponges were the dominant sessile invertebrates on these rock faces and their cover was usually positively associated with the density of Austrobalanus (Davis $\&$ Ward 1999). Approximately 10 sponge species were commonly encountered at each site, although 4 species, Chondrilla australiensis, Clathria pyramida, Darwinella australiensis and Tedania anhelans, accounted for $>65 \%$ of the invertebrate cover (Wright et al. 1997, A. R. Davis unpubl. data).

Urchin grazing intensity and barnacle density. A relative measure of urchin grazing intensity was obtained by quantifying the percentage cover of paint removed from $25 \mathrm{~mm}$ plastic discs, as described by Ayling (1981). Fifty discs were glued haphazardly across $\sim 50 \mathrm{~m}$ of vertical surfaces at 2 locations, Flinders Islet near Wollongong and Dart Point in Jervis Bay, with a 2-part epoxy (Z-Spar A-788 Splash Zone Epoxy). Discs were removed $10 \mathrm{~d}$ later and the density of Austrobalanus was quantified within a $25 \times 25 \mathrm{~cm}$ quadrat centered on each disc. Discs were scanned, and the loss of paint was traced and estimated with Image (http://rsbweb.nih.gov/ij/). Loss of paint was then regressed against barnacle density. Removal and subsequent reintroduction of urchins in a pilot experiment confirmed that urchins had removed the paint from discs (A. R. Davis unpubl. data). The characteristic scraping pattern of urchins was clearly visible on the discs.

Barnacle addition. To examine the role of Austrobalanus in the establishment of encrusting assemblages on vertical walls, we manipulated barnacle density at 2 locations near Wollongong: Redsands Reef and Flinders Islet. Locations were treated as a random factor in the subsequent analysis to provide some generality to the southeastern Australian coast. Each location was divided into 2 sites. Sixteen $0.18 \mathrm{~m}^{2}$ plots were delineated haphazardly on coralline-algal-encrusted vertical rock faces and the sides of large boulders at each site. We did not place plots over established barnacles, as we reasoned that their removal might leave small fragments of sponge with the potential to regrow. Each site was $\sim 50 \mathrm{~m}$ in diameter, and plots were not placed one above the other. Plots were marked with $6 \mathrm{~mm}$ stainless steel masonry Dynabolts (Ramset) anchored into 3 corners of each plot. Four treatments were then randomly assigned to plots within each site $(\mathrm{N}=4)$. These treatments were control $(0)$, low (10), medium (20) and high (40) barnacle densities, spanning the range of densities regularly encountered on natural rock surfaces. The tests of dead barnacles were glued in place with a 2-part epoxy (Z-Spar A-788 Splash Zone Epoxy). In addition, small blobs of epoxy were fixed to the zero-density control plots, so that epoxy was present on all treatment plots. The few barnacles detached from the rock surface during the experiment were replaced at regular intervals. We used barnacle tests in these experiments, as attempts to transplant living barnacles proved unsuccessful. The barnacles (basal width $37.4 \pm 5.1 \mathrm{~mm}$, mean $\pm \mathrm{SD}$ ) were removed from neighboring areas and transferred to the laboratory, where all tissues were removed and the tests filled with 2-part epoxy (K340 Araldite, CibaGeigy). To facilitate barnacle attachment, the bare rock face in all treatment and control plots was scrubbed with a wire brush prior to the application of epoxy. Care was taken to minimize disturbance to gastropods on the plots during brushing.

In addition to imitating naturally occurring barnacle densities, the position and orientation of barnacles within treatment plots replicated those of naturally occurring barnacles. Clear flexible plastic templates were used to ensure that barnacles were fixed in realistic spatial patterns. Templates were made by projecting photographs of Austrobalanus onto the perspex and marking the position of the barnacles. Eight templates were used for each barnacle density $(10,20$ or 40). Thus, each template was used only once at each location. The fixing of barnacles was completed in March 1995 at Redsands Reef and in April 1995 at Flinders Islet. Sessile invertebrates were counted directly in the plots at each site approximately 4 mo later. Plots were then photographed at regular intervals until November/December 1999. The camera and strobe (Nikonos V with $28 \mathrm{~mm}$ lens and SB102 strobe) were mounted on a frame with a lens-to-subject distance of $60 \mathrm{~cm}$. The cover of sessile invertebrates was estimated by counting invertebrates below 300 regularly arranged dots on images of each $0.18 \mathrm{~m}^{2}$ plot. Species richness was quantified by counting the number of sessile invertebrate species visible on each photograph. We provide a time course for these data based on analysis on 2 occasions: at 8 mo and 56 mo after the experiment was initiated. We make the assumption that the intervening 48 mo renders the data effectively independent. Assumptions of all analyses were examined prior to proceeding with the analysis. For ANOVA, normality was assessed visually and Cochran's $C$-test was used to ensure that variances were homogeneous. Data were transformed where necessary. We used G-MAV5 (University of Sydney) for ANOVA and non-parametric multivariate analysis of variance or PRIMER for multivariate analysis.

As we examined hypotheses relating to invertebrate recruitment, we excluded the cover of invertebrates encroaching onto the plots from beyond their borders. Inclusion of the cover or species richness of encroaching invertebrates had little effect on the respective means and did not change the outcome or our interpretation. In testing the prediction that invertebrate 
recruitment increases with increasing barnacle density, we also ignored the area on the plots that was covered by the barnacle tests we had fixed in place. Recruitment directly onto these barnacle tests was only rarely observed. In addition, as the presence of these tests reduced the space available on each plot for recruits, plots with the highest density of barnacle tests should have the lowest recruits, providing a conservative test of our hypothesis. We also recorded the density of urchins prior to the addition of barnacles with 10 haphazardly placed $10 \times 1 \mathrm{~m}$ transects within each site at each location. Urchin densities were reassessed in the same way in December 1999.

Barnacle removal. To determine whether an established assemblage could maintain itself once subjected to grazing by Centrostephanus rodgersii, we removed living Austrobalanus from plots at Flinders Islet, Wollongong and Longnose Point, Jervis Bay. Each location was divided into 2 sites, each $\sim 50 \mathrm{~m}$ in diameter. Twelve plots measuring $0.18 \mathrm{~m}^{2}$ were delineated on vertical rock surfaces at each site. We selected plots with medium to high Austrobalanus densities (> 20 ind. plot $^{-1}$ ) and a large cover of sponges, the predominant invertebrate taxon. Three treatments were then assigned randomly amongst plots $(\mathrm{N}=4)$ : (1) total barnacle removal, (2) procedural control-partial removal of sponges without barnacle removal (this controlled for sponge damage during barnacle removal), and (3) unmanipulated control. Barnacles and sponges were removed using a hammer and paint scraper. We ensured that all barnacle flesh was removed from each manipulated plot so as not to attract grazers or predators. Plots were marked with stainless steel masonry Dynabolts as in the previous experiment. The experiment was initiated in June 1995 at Flinders Islet and July 1995 at Longnose Point, and the plots were photographed at regular intervals until April 1997. Analyses proceeded as in the previous experiment.

\section{RESULTS \\ Urchin grazing intensity and the addition of barnacles}

The loss of paint from the grazing discs implied a negative relationship between urchin grazing intensity and barnacle density (Fig. 1). The relationship appeared curvilinear at Flinders Islet $\left(\mathrm{r}^{2}=0.28, \mathrm{~N}=39\right.$, $\left.y=37.57 \times 10^{-0.03 x}\right)$ and linear at Dart Point $\left(r^{2}=0.26\right.$, $\mathrm{N}=47, y=-0.70+48.48)$ and both regressions were significant at $\mathrm{p}<0.001$.

The addition of barnacles markedly influenced patterns of invertebrate recruitment. Counts of sessile invertebrates $4 \mathrm{mo}$ after the experiment was initiated revealed treatment $\left(F_{3,3}=17.0, \mathrm{p}=0.022\right)$ and site $\left(F_{2,48}=6.02, \mathrm{p}=0.005\right)$ effects, but no significant interaction terms (Fig. 2; Table 1). The average number of invertebrates (predominantly bryozoans) was consistently greater on plots to which barnacles had been added than on control plots (Fig. 2). A posteriori Student-Newman-Keuls tests revealed that these differences were significant and also that invertebrates were more abundant at Site 1 than at Site 2 at Flinders Islet, while similar numbers were apparent at the 2 sites at Redsands Reef. The addition of barnacles also increased species diversity, as measured by the Shannon-Wiener diversity index and the evenness of the developing assemblage $\left(F_{3,3}=31.9, \mathrm{p}=0.009 ; F_{3,3}=\right.$ $17.8, \mathrm{p}=0.02$, respectively). On average, the abundance of invertebrates on plots with high densities of barnacles was 10-fold that on control plots (Fig. 2).

Seven to $8 \mathrm{mo}$ after barnacles were added to plots, invertebrate cover averaged $>8 \%$ at both sites in plots that had received high densities of barnacles (Fig. 3). This was $>4$-fold higher than in the plots with low and medium barnacle densities and $>35$-fold higher than

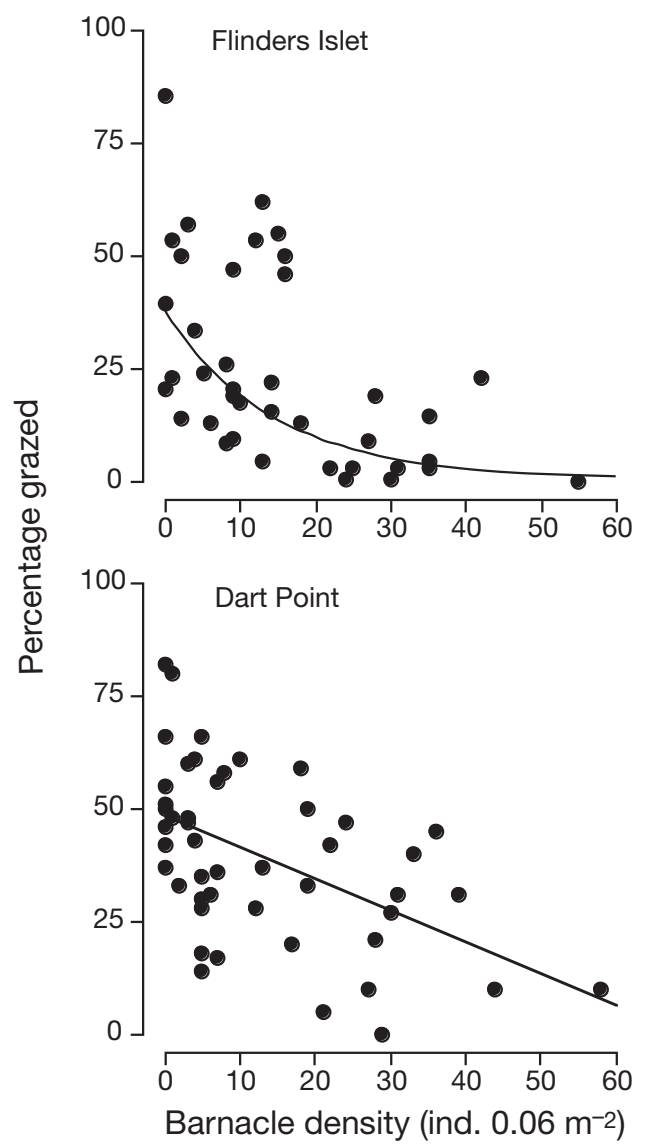

Fig. 1. Urchin grazing intensity as a function of barnacle density. Grazing intensity was estimated as the percentage of paint removed from plastic discs by urchins following $10 \mathrm{~d}$ of deployment 
in the control plots. ANOVA revealed a significant treatment effect $\left(F_{3,3}=14.8, \mathrm{p}=0.02\right)$ and StudentNewman-Keuls tests confirmed that the high-density treatment was significantly different from the other 3

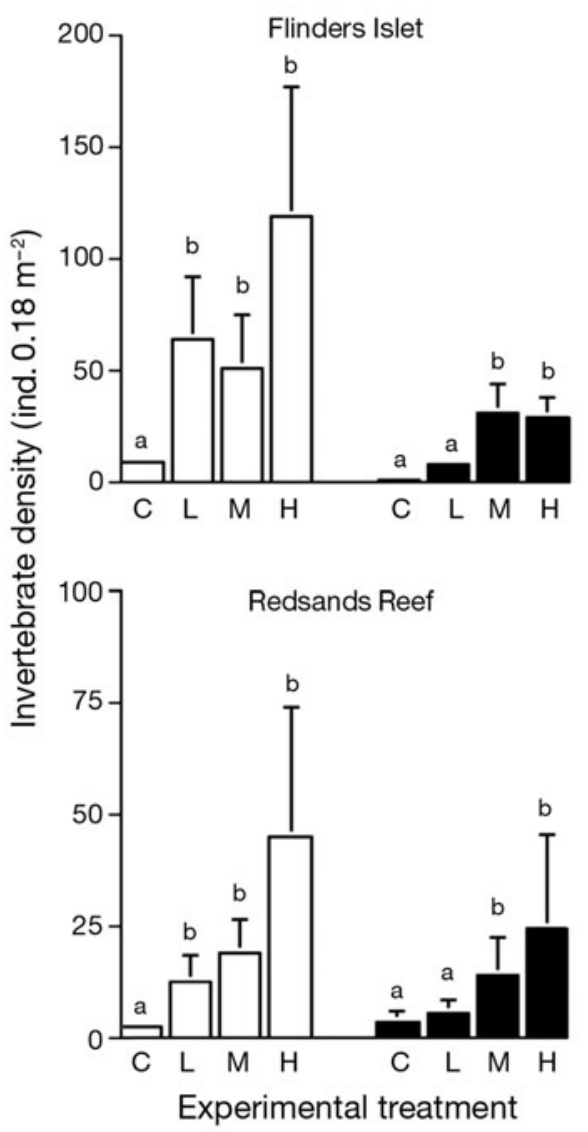

Fig. 2. Invertebrate densities (mean $\pm \mathrm{SE}$ ) within control and barnacle addition plots 4 mo after the experiment was initiated ( $\mathrm{N}=4$ quadrats). Two sites are displayed at each location: Site $1(\square)$, Site 2 (匹). C: control; L: low; M: medium and $\mathrm{H}$ : high barnacle additions. Bars bearing the same letters $(\mathrm{a}, \mathrm{b})$ are not significantly different treatments (Table 2). Although a similar pattern was apparent for species richness, the differences were not significant $\left(F_{3,3}=6.4, \mathrm{p}=0.08\right)$.

Although the high cover of invertebrates in plots containing high barnacle densities relative to other treatments was maintained for the next 2 yr, no differences among treatments were detected by December $1999\left(F_{3,3}=1.13, \mathrm{p}=0.461\right.$; Table 2$)$. Even the cover of invertebrates on the control plots at Redsands Reef was indistinguishable from that on the high-density plots at this site (Fig. 3). An ANOVA of the December 1999 data confirmed that the only significant treatment effect was location $\left(F_{1,2}=38.5, \mathrm{p}=0.025\right)$, invertebrate cover being higher at Flinders Islet (Table 2). In contrast, the number of sessile invertebrate species was higher in the plots receiving high densities of barnacles than in the controls $\left(F_{3,3}=10.1, p=0.045\right.$, Fig. 3 ; Table 2). Hence, the patterns in species richness seen in December 1995, which were bordering on significant $\left(F_{3,3}=6.4, \mathrm{p}=0.08\right)$, were still apparent $4.5 \mathrm{yr}$ after the experiment was begun. Again, the inclusion of encroaching invertebrates into the data set made little difference to average cover or species richness and did not change our interpretation.

By February 1998, the cover and composition of plots used in our manipulation were strikingly different from areas of unmanipulated natural reef. The average invertebrate cover in treatment and control plots (now including encroaching invertebrates) did not exceed $10 \%$. In contrast, a series of photographs taken haphazardly on nearby vertical surfaces in February 1998 revealed an average sessile invertebrate cover $>23 \%$ at each location (Fig. 4). These values exclude the cover of Austrobalanus, as this barnacle was manipulated in the treatment plots and, therefore, it was inappropriate to include estimates of its cover. Barnacles and bryozoans dominated treatment plots, whereas sponges dominated unmanipulated areas on rock

Table 1. ANOVA results for the effects of different factors on the number and diversity (Shannon-Wiener Index $H^{\prime}$ and Evenness) of invertebrate colonies 4 mo after start of the experiment. The data exclude species encroaching from the border. Factors were Location (L) (random) with 2 levels, Site (S) nested within Location (random) with 2 levels, and Treatment (T) (fixed, with 4

levels of barnacle density: zero, low, medium and high) crossed with factors 1 and $2 . \mathrm{N}=4$ quadrats. ${ }^{*} \mathrm{p}<0.05,{ }^{* *} \mathrm{p}<0.01$

\begin{tabular}{|c|c|c|c|c|c|c|c|c|}
\hline \multirow[t]{2}{*}{ Source } & \multirow[t]{2}{*}{$\mathrm{df}$} & \multirow{2}{*}{$\begin{array}{c}\text { F-ratio } \\
\text { vs. }\end{array}$} & \multicolumn{2}{|c|}{ No. of ind. } & \multicolumn{2}{|c|}{$H^{\prime}$} & \multicolumn{2}{|c|}{ Evenness } \\
\hline & & & MS & $F$ & MS & $F$ & MS & $F$ \\
\hline Location & 1 & $\mathrm{~S}(\mathrm{~L})$ & 7.7 & 1.0 & 0.07 & 0.42 & 0.004 & 0.17 \\
\hline Site(L) & 2 & RES & 7.7 & $6.02^{* *}$ & 0.17 & 1.35 & 0.226 & 0.29 \\
\hline Treatment & 3 & LXT & 13.7 & $17.0^{*}$ & 1.39 & $31.88^{* *}$ & 0.865 & $17.79^{*}$ \\
\hline Location $\times$ Treatment & 3 & TXS(L) & 0.8 & 0.94 & 0.04 & 0.19 & 0.048 & 0.26 \\
\hline Treatment × S(L) & 6 & RES & 0.9 & 0.67 & 0.23 & 1.89 & 0.188 & 2.04 \\
\hline Residual & 48 & & 1.3 & & 0.12 & & 0.092 & \\
\hline Total & 63 & & & & & & & \\
\hline Transformation & & & $\ln (x+1)$ & & None & & None & \\
\hline Cochran's $C$ & & & 0.164 & & 0.142 & & 0.179 & \\
\hline
\end{tabular}



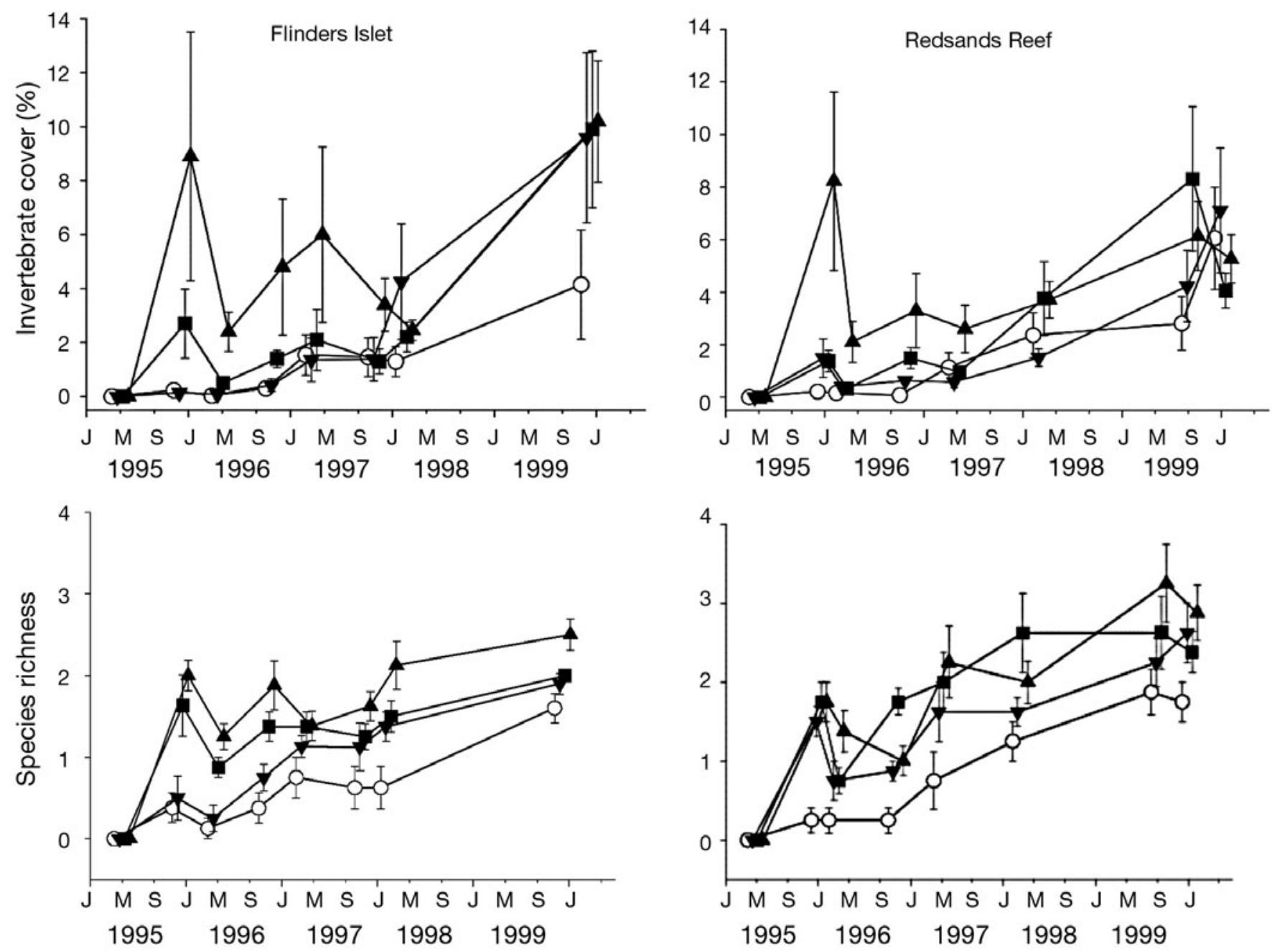

Fig. 3. Percentage cover and species richness (mean \pm SE) of sessile invertebrates within control and barnacle addition plots at Flinders Islet and Redsands Reef as a function of time. Four barnacle densities were used: control $(O)$, low $(\mathbf{\nabla})$, medium ( $(\mathbf{\square})$ and high (ム). J: January; M: May; S: September. Data exclude invertebrates encroaching onto plots from beyond their borders and were pooled across sites ( $\mathrm{N}=8$ quadrats)

Table 2. ANOVA results for the effects of Location, Site and Treatment (barnacle addition) on \% cover and diversity of invertebrate colonies 8 mo (December 1995) and 56 mo (December 1999) after start of the experiment. These data exclude species encroaching from the border. Factors, treatments and $F$-ratio denominators are as for Table $1 . \mathrm{N}=4$ quadrats. ${ }^{*} \mathrm{p}<0.05$

\begin{tabular}{|c|c|c|c|c|c|c|c|c|c|}
\hline \multirow[t]{3}{*}{ Source } & \multirow[t]{3}{*}{$\mathrm{df}$} & \multicolumn{4}{|c|}{ December 1995} & \multicolumn{4}{|c|}{ December 1999} \\
\hline & & \multicolumn{2}{|c|}{$\%$ cover } & \multicolumn{2}{|c|}{ SR } & \multicolumn{2}{|c|}{$\%$ cover } & \multicolumn{2}{|c|}{ SR } \\
\hline & & MS & $F$ & MS & $F$ & MS & $F$ & MS & $F$ \\
\hline Location & 1 & 3.4 & 0.13 & 0.56 & 4.5 & 89.9 & $38.5^{*}$ & 2.64 & 6.76 \\
\hline Site(Location) & 2 & 25.8 & 0.63 & 0.12 & 0.27 & 2.3 & 0.05 & 0.39 & 0.82 \\
\hline Treatment & 3 & 510.9 & $14.8^{*}$ & 8.1 & 6.38 & 56.3 & 1.13 & 2.68 & $10.10^{*}$ \\
\hline Location $\times \mathrm{T}$ & 3 & 34.5 & 1.65 & 1.27 & 2.18 & 49.7 & 3.63 & 0.26 & 0.48 \\
\hline Treatment $\times \mathrm{S}(\mathrm{L})$ & 6 & 20.9 & 0.51 & 0.58 & 1.24 & 13.7 & 0.27 & 0.55 & 1.18 \\
\hline Residual & 48 & 40.9 & & 0.46 & & 51.2 & & 0.47 & \\
\hline Total & 63 & & & & & & & & \\
\hline Transformation & & Arcsin & & None & & Arcsin & & None & \\
\hline Cochran's $C$ & & $0.324^{*}$ & & 0.222 & & 0.152 & & 0.176 & \\
\hline
\end{tabular}




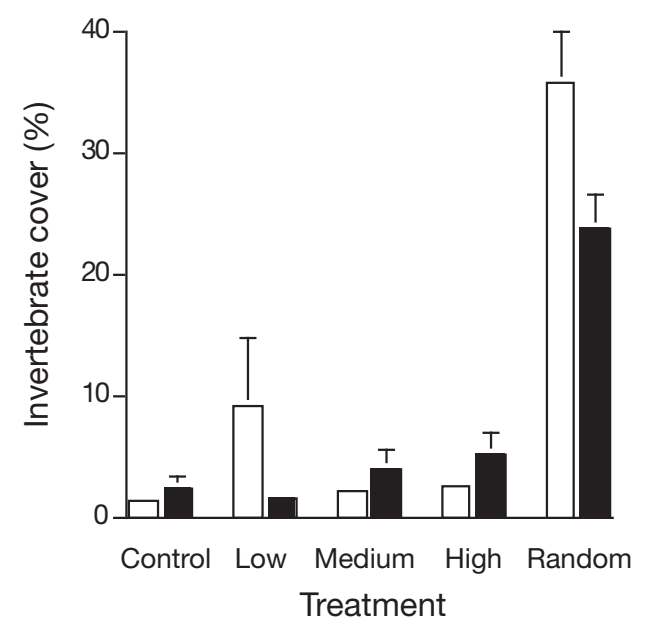

Fig. 4. Mean cover ( \pm SE) of invertebrates on rock walls within the control and barnacle addition plots and on unmanipulated plots (Random). Data are presented for 2 locations: Flinders Islet ( $\square$ ) and Redsands Reef (ם). For details on barnacle additions, see 'Materials and methods'

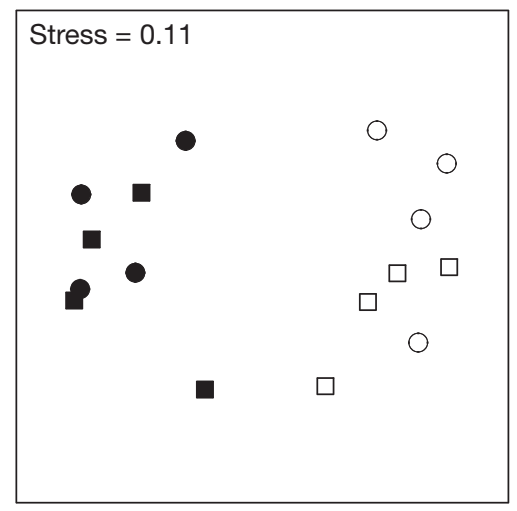

Fig. 5. Non-metric MDS plot of the abundance of sessile invertebrates on plots to which barnacles were added and on unmanipulated vertical surfaces at Flinders Islet and Redsands Reef. Each symbol represents a mean (centroid) for 8 plots (sites within locations were pooled). Flinders Islet treatment plots $(\boldsymbol{\square})$, random plots on unmanipulated walls ( $\square$ ), Redsands Reef treatment plots $(\bullet)$ and random plots on unmanipulated walls (O)

walls. These differences in composition were clearly displayed by a non-metric MDS (Fig. 5). A 2-way crossed multivariate ANOVA confirmed that the composition of natural vertical surfaces differed from that of treatment plots $(F=13.59, \mathrm{p}=0.005)$ and that locations were bordering on significantly different at the $5 \%$ level $(F=2.42, \mathrm{p}=0.071)$. No significant interaction was apparent. The average Bray-Curtis measure of dissimilarity between the natural locations and treatment plots was $68.2 \%$, and a SIMPER analysis indi- cated that sponges were largely responsible for this. In descending rank, these were Tedania anhelans, Darwinella australiensis, Clathria pyramida, Culicia cf. tenella, Callyspongia sp. and Chondrilla australiensis (Table 3).

Urchin densities were high during the course of this experiment, with a maximum of $108 \pm 7$ ind. $10 \mathrm{~m}^{-2}$ (mean \pm SE) (Fig. 6). The lowest densities recorded were around half of this number. There were significant differences between sites within each location in the pre-manipulation assessment of urchin density (significant 'Time $\times$ Site [Location]' interaction, Table 4). However, there were no differences in densities between years at either site $\left(F_{1,1}=2.13, \mathrm{p}=0.38\right.$; Table 4).

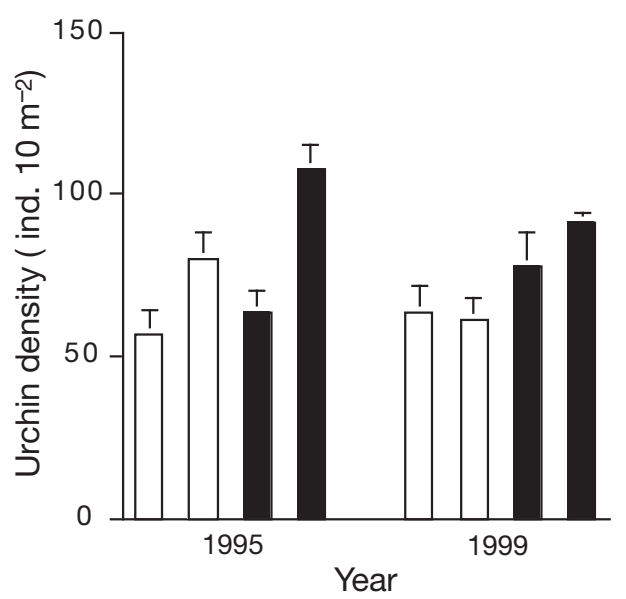

Fig. 6. Density (mean $\pm \mathrm{SE}$ ) of the sea urchin Centrostephanus rodgersii at Flinders Islet ( $\square$ ) and Redsands Reef ( $\square$ ) at the beginning (March 1995) and end (December 1999) of the barnacle addition experiment. Data are based on $10 \times 1 \mathrm{~m}$ transects and are presented for each site ( $\mathrm{N}=10$ transects). The first bar for each location is Site 1 and the second is Site 2

Table 3. Species, ranked in order of importance (only the first 6 are presented), which contributed to the dissimilarity between barnacle addition plots and unmanipulated plots on rock walls. Determined using SIMPER

\begin{tabular}{|c|c|c|c|c|}
\hline Species & Phylum & $\begin{array}{c}\text { Invertebrate } \\
\text { Unmanip- } \\
\text { ulated } \\
\text { plots }\end{array}$ & $\begin{array}{l}\text { cover \% } \\
\text { Treat- } \\
\text { ment } \\
\text { plots }\end{array}$ & $\begin{array}{l}\text { Cumu- } \\
\text { lative } \\
\text { percent- } \\
\text { age }\end{array}$ \\
\hline Tedania anhelans & Porifera & 5.57 & 0.01 & 13.51 \\
\hline $\begin{array}{l}\text { Darwinella } \\
\text { australiensis }\end{array}$ & Porifera & 6.60 & 0.18 & 26.72 \\
\hline Clathria pyramida & Porifera & 3.49 & 0.00 & 36.77 \\
\hline Culicia tenella & Cnidaria & 3.73 & 0.03 & 46.52 \\
\hline Callyspongia sp. & Porifera & 2.22 & 0.00 & 55.40 \\
\hline $\begin{array}{l}\text { Chondrilla } \\
\text { australiensis }\end{array}$ & Porifera & 3.77 & 0.00 & 63.87 \\
\hline
\end{tabular}




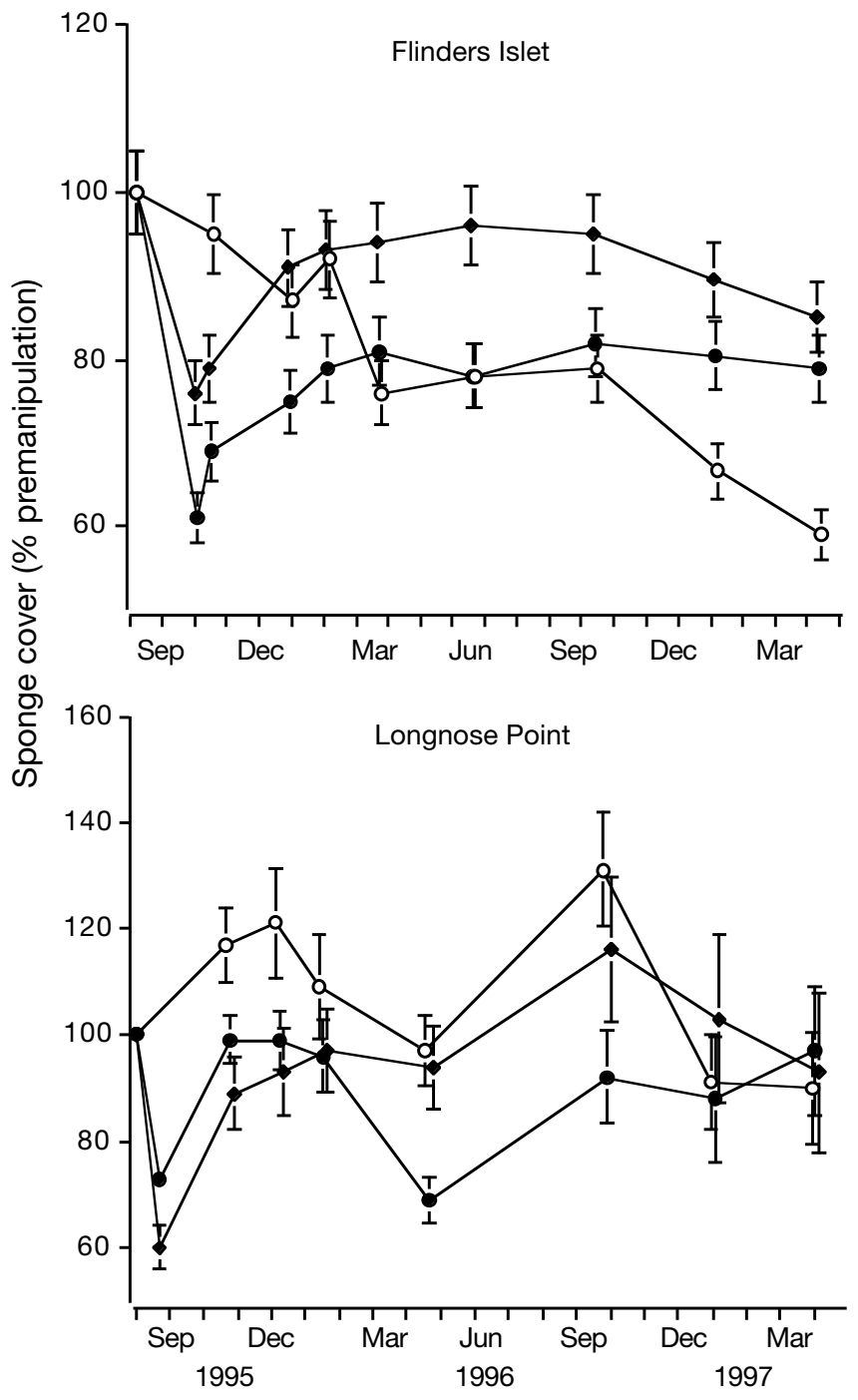

Fig. 7. Percentage cover (mean \pm SE) of sponges following experimental removal of the barnacle Austrobalanus imperator at Flinders Islet and Longnose Point as a function of time. Data are presented as sponge percentage cover relative to the starting cover of sponges within each plot. Three treatments are presented: unmanipulated control $(O)$, procedural control $(\bullet$, i.e. removal of sponge leaving barnacles untouched) and barnacle removal $(\bullet)$, which also results in damage to sponges. Data were pooled across sites ( $\mathrm{N}=8$ quadrats)

\section{Barnacle removal}

Sponges were able to maintain space after the large barnacle had been removed, and consistent patterns were observed between the 2 locations and within sites (Fig. 7). The data are presented for each location as means pooled across the sites. Initially, with the removal of barnacles and in the sponge removal (procedural control), the cover of sponges fell by around $40 \%$, but within 3 mo sponges recovered and cover among the 3 treatments was judged not significantly
Table 4. ANOVA results for the effects of different factors on the density of sea urchins Centrostephanus rodgersii. Factors were Site (S) nested within Location (L) (both random) and Time (T) (fixed) with 2 levels (pre- and and post-barnacle manipulation). Data were derived from $1 \times 10 \mathrm{~m}$ transects at each site. $\mathrm{N}=10$ transects

\begin{tabular}{|lrcrcl|}
\hline Source & df & $\begin{array}{c}\text { F-ratio } \\
\text { vs. }\end{array}$ & MS & $F$ & P \\
\hline Location & 1 & S(L) & 8040.0 & 1.69 & 0.32 \\
Site $($ Location) & 2 & RES & 4764.5 & 8.56 & 0.0005 \\
Time & 1 & LXT & 245.0 & 2.13 & 0.38 \\
Location $\times$ Time & 1 & TXS(L) & 115.2 & 0.06 & 0.83 \\
Time $\times$ S(L) & 2 & RES & 2020.5 & 3.63 & 0.031 \\
Residual & 72 & & 556.5 & & \\
Total & 79 & & & & \\
Transformation & & & None & & \\
Cochran's C & & & 0.227 & & \\
\hline
\end{tabular}

different (Table 5). After 6 mo, sponges in treatment plots had attained pre-manipulation levels. At the conclusion of the experiment, after $22 \mathrm{mo}$, plots from which barnacles had been removed were indistinguishable from the procedural controls. However, at Flinders Islet, the cover of the unmanipulated control had fallen below $60 \%$ of the pre-manipulation cover, producing a significant Location $\times$ Treatment interaction (Fig. 7; Table 5).

\section{DISCUSSION}

The large barnacle Austrobalanus played an important functional role in the establishment, but not persistence, of benthic invertebrate assemblages in southeastern Australia. On the one hand, the addition of barnacles to plots had a clear and rapid influence on invertebrate recruitment, reflected by the elevated cover and species richness in the plots receiving the highest density of barnacles. Bryozoans and, to a lesser extent, barnacles responded rapidly to the addition of structure (tests of Austrobalanus) and were recruited in high numbers. Plots to which we glued barnacles in high densities (40) had the highest invertebrate species richness, and this was maintained until the end of our 5 yr study. On the other hand, the effect of barnacle density on invertebrate cover diminished over time, and, by the end of the study, the cover of invertebrates in treatment plots did not differ significantly from that in control plots. This was due to an increase in cover on the control and low-density plots and reflected asexual growth of modular organisms on these plots. Thus, our initial prediction that the presence of barnacles would enhance the cover and diversity of sessile invertebrates was supported in the short term (first $8 \mathrm{mo}$ ), but 
Table 5. ANOVA results for the effects of different factors on the percentage cover of sponges 6 mo (October 1995) and 22 mo (April 1997) after start of the experiment. Factors were Site (S) nested within Location (L) (both random) and Treatment ( $T$, barnacle removal) (fixed) with 3 levels (unmanipulated control, procedural control and barnacle removal). $\mathrm{N}=4$ quadrats. ${ }^{*} \mathrm{p}<0.05$

\begin{tabular}{|c|c|c|c|c|c|c|}
\hline \multirow{2}{*}{ Source } & \multirow[t]{2}{*}{ df } & \multirow{2}{*}{$\begin{array}{c}\text { F-ratio } \\
\text { vs. }\end{array}$} & \multicolumn{2}{|c|}{ October 1995} & \multicolumn{2}{|c|}{ April 1997} \\
\hline & & & MS & $F$ & MS & $F$ \\
\hline Location & 1 & $\mathrm{~S}(\mathrm{~L})$ & 2174 & 11.98 & 0.07 & 0.42 \\
\hline Site(Location) & 2 & RES & 181 & 0.36 & 0.17 & 1.35 \\
\hline Treatment & 2 & LXT & 1948 & 2.47 & 1.39 & 31.88 \\
\hline Location $\times$ Treatment & 2 & TXS(L) & 788 & 3.17 & 0.19 & 0.048 \\
\hline Treatment $\times \mathrm{S}(\mathrm{L})$ & 4 & RES & 249 & 0.49 & 0.23 & 1.89 \\
\hline Residual & 36 & & 505 & & 0.12 & \\
\hline Total & 47 & & & & & \\
\hline Transformation & & & None & & None & \\
\hline Cochran's $C$ & & & $0.38^{*}$ & & 0.22 & \\
\hline
\end{tabular}

vivorship of sessile invertebrates (Dean \& Hurd 1980, Dean 1981, Keough \& Downes 1982, Sebens 1991, Walters \& Wethey 1991, Walters 1992, Guichard \& Bourget 1998). However, much of our understanding of benthic invertebrate assemblages associated with hard substrata comes from detailed studies of artificial surfaces, particularly pier pilings or small settlement panels (Karlson 1978, Kay \& Butler 1983, Butler \& Connolly 1999). These habitats, although useful and convenient model systems, differ substantially from natural urchin-dominated systems. On pilings for example, sea urchins are usually absent, light levels and the cover of encrusting was not borne out for the cover of invertebrates over the longer term. Changes in cover did not appear to be due to reductions in grazing intensity, as urchin densities did not change over the course of the experiment.

As we predicted, barnacles did not appear to play a role in maintaining a sponge-dominated invertebrate assemblage, once members of that assemblage were well established. The removal of barnacles from plots with a relatively high cover of sponges resulted in the rapid recovery of the space lost by sponges during the experimental removal. Within 6 mo of the manipulation, no significant differences in sponge cover, relative to starting cover, were apparent in treatment plots at either location. Many encrusting temperate sponges show rapid regrowth in response to damage (Kay \& Keough 1981, Ayling 1983), although growth rates can vary considerably among sponge species (Kay \& Keough 1981). Urchins can have dramatic impacts on sessile invertebrates (Vance 1979, Himmelman et al. 1983, Sebens 1986), but we suspect that chemical or physical defenses deterred urchins from feeding on sponges once barnacles were removed. Antifeedant activity has been demonstrated for a number of the major space-occupying sponges in urchin barrens of our region (Wright et al. 1997, Ferguson \& Davis 2008).

A growing body of literature attests to the importance of habitat complexity in the structure and function of assemblages (MacArthur \& MacArthur 1961, Hixon \& Menge 1991, Talman et al. 2004). In marine systems, structural complexity has been linked to enhanced diversity (Castilla et al. 2004, Eriksson et al. 2006, Hauser et al. 2006), but usually this is inferred from snapshots of data collected over short time frames rather than following a time course of several years. The persistence of an effect after 56 mo in our highdensity treatments was particularly striking. Habitat complexity may also determine the settlement and sur- algae are low, and the diversity and cover of invertebrates are usually very high. One of the few studies of the response of sessile invertebrates to the addition of barnacle tests used small glass plates $\left(25 \mathrm{~cm}^{2}\right)$ as substrata, and these were suspended $10 \mathrm{~cm}$ above the substratum for short periods of time (Bros 1987). Conclusions from such studies must be considered tentative.

The changes we observed following the addition of barnacles are consistent with our assertion that aggregations of the large barnacle Austrobalanus interfere with the grazing activities of sea urchins, thereby creating refugia for sessile invertebrates. Nevertheless, alternative hypotheses are worthy of attention, as the presence of barnacles will influence hydrodynamics, and the disruption to water flow may in turn influence patterns of invertebrate settlement and recruitment (Eckman 1983, Littler et al. 1983, Guichard \& Bourget 1998, Walters et al. 1999). For a refuge to be effective, it must persist in the face of disturbance and hence offer spatial and temporal predictability to those species to which it offers refuge (Woodin 1981). Witman (1985) noted that life-history attributes of the refugeforming mussel Modiolus, namely its slow growth and longevity, contribute to its ability to form a long-term refuge. In southeastern Australia, Austrobalanus also appears to persist for many years. Although no published studies of longevity or mortality have been undertaken for Austrobalanus, mortality in photoquadrats in the present study was low and potential barnacle predators such as starfish and whelks were rare in the barrens habitat. Hence, Austrobalanus appears to form persistent clumps that are predictable in space and time. If, as we assert, Austrobalanus forms a persistent refuge from urchin grazing, then the evolution of habitat selection is likely (Woodin 1981). As invertebrate recruitment is enhanced near Austrobalanus, it may be disadvantageous for poor competitors 
to settle near them. Several studies have reported the avoidance of substrata preferred by strong competitors, such as ascidians, by the competent larvae of invertebrates that are poor competitors (Grosberg 1981, Young \& Chia 1981). Davis \& Ward (1999) noted that the abundance of one of the dominant sponges in our system, Clathria pyramida, shows a strong negative relationship with barnacle density. If C. pyramida is a poor competitor for space, its larvae may avoid settling near aggregations of barnacles. This is an interesting hypothesis for further study.

Our findings are consistent with the notion that Austrobalanus modifies settlement or post-settlement mortality among sessile invertebrates. Data from the grazing discs we deployed revealed a negative relationship between urchin grazing intensity and the density of barnacles, supporting our contention that patches of Austrobalanus provide invertebrates with a refuge from urchin grazing, at least in the short term. Other authors have noted the important role of structure in modifying the foraging activities of predators in shallow subtidal assemblages (Russ 1980, Hixon \& Brostoff 1983, Witman 1985, Littler et al. 1986, Sebens 1991). However, to unambiguously assign the patterns we have observed to the creation of grazing refugia by the structure-forming barnacle requires experimental manipulation of urchin densities.

The development of the invertebrate assemblage in our study did not approach that of unmanipulated rock walls. Specifically, the cover and composition of invertebrates recruiting to the treatment plots were strikingly different from those found on unmanipulated rock surfaces, even after almost 5 yr. Whereas the average cover of invertebrates on unmanipulated surfaces approached $25 \%$, the treatment plots did not exceed an average cover of $10 \%$ (Fig. 4). Unmanipulated walls were dominated by several sponge species, while treatment plots had large numbers of barnacles, bryozoans and sponge species not commonly observed in unmanipulated areas, as reflected in the non-metric MDS ordination (Fig. 5). It appears that many of the major space occupiers on the unmanipulated walls, particularly the sponges Clathria pyramida, Darwinella australiensis and Tedania anhelans, recruited only rarely to our experimental plots over the $5 \mathrm{yr}$ period, and those that did failed to persist. Sponges are among the dominant organisms on vertical surfaces in temperate waters (Sebens 1985, 1991) but recruit infrequently to settlement panels used to examine the development of sessile invertebrate assemblages (Dean \& Hurd 1980, Breitburg 1985, Glasby 1998). Only when panels were placed close to a high cover of sponges has appreciable sponge recruitment been observed (Kay \& Keough 1981, Butler 1986, 1991). It is also clear that recruitment may be an important mechanism main- taining diversity in subtidal epifaunal assemblages (Smith \& Witman 1999).

We are left, then, with a complex picture. Clumps of Austrobalanus play an important functional role, at least in the short term, as they contribute to the structural complexity and architecture of vertical rock walls. The biogenic structure they impart in turn influences patterns of diversity and, to a lesser extent, the cover of sessile invertebrates. The unexpected outcome was that the assemblage that develops bears little similarity to those observed on unmanipulated rock walls. The slow rate of colonization observed in our experimental plots raises the possibility that largescale (geographic) variation in rates of recruitment has important implications for the structure and dynamics of temperate reef invertebrate assemblages, a pattern already observed in the rocky intertidal zone (Underwood \& Denley 1984). Our findings from natural rocky reefs highlight the likelihood that, in the case of sponges and perhaps other long-lived sessile invertebrates, we may be using inappropriate spatial or temporal scales to examine the ecology of these important occupiers of space.

Acknowledgements. Financial support was provided for this project by the Australian Research Council and the Institute for Conservation Biology, University of Wollongong. We are indebted to K. Ganassin. P. Grevenitz and S. Murray-Jones for their assistance in the field, while some of the photo-interpretation was undertaken by S. Waters. G. Quinn provided advice on matters statistical. Comments on early drafts by T. Minchinton, J. Himmelman, L. Walters, A. Broad and $\mathrm{K}$. Benkendorff clarified and improved the manuscript. This is contribution no. 286 from the Ecology and Genetics Group, University of Wollongong.

\section{LITERATURE CITED}

Addicott JF, Aho JM, Antolin MF, Padilla DK, Richardson JS, Soluk DA (1987) Ecological neighborhoods: scaling environmental patterns. Oikos 49:340-346

Andrew NL (1993) Spatial heterogeneity, sea urchin grazing, and habitat structure on reefs in temperate Australia. Ecology 74:292-302

Ayling AM (1981) The role of biological disturbance in temperate subtidal encrusting communities. Ecology 62: 830-847

Ayling AL (1983) Factors affecting the spatial distributions of thinly encrusting sponge from temperate waters. Oecologia 60:412-418

Bell SS, McCoy ED, Mushinsky HR (eds) (1991) Habitat structure: the physical arrangement of objects in space. Chapman \& Hall, London

> Breitburg DL (1985) Development of a subtidal epibenthic community: factors affecting species composition and the mechanisms of succession. Oecologia 65:173-184

Bros WE (1987) Effects of removing or adding structure (barnacle shells) on recruitment to a fouling community in Tampa Bay, Florida. J Exp Mar Biol Ecol 105:275-296

Butler AJ (1986) Recruitment of sessile invertebrates at five 
sites in Gulf St. Vincent, South Australia. J Exp Mar Biol Ecol 97:13-36

Butler AJ (1991) Effects of patchsize on communities of sessile invertebrates in Gulf St Vincent, South Australia. J Exp Mar Biol Ecol 153:255-280

Butler AJ, Connolly RM (1999) Assemblages of sessile marine invertebrates: Still changing after all these years? Mar Ecol Prog Ser 182:109-118

Castilla JC, Lagos NA, Cerda M (2004) Marine ecosystem engineering by the alien ascidian Pyura praeputialis on a mid-intertidal rocky shore. Mar Ecol Prog Ser 268: $119-130$

Connell JH (1961) The influence of interspecific competition and other factors on the distribution of the barnacle Chthamalus stellatus. Ecology 42:710-723

> Coyer JA, Ambrose RF, Engle JM, Carroll JC (1993) Interactions between corals and algae on a temperate zone rocky reef: mediation by sea urchins. J Exp Mar Biol Ecol 167: $21-37$

> Creese RG (1982) Distribution and abundance of the acmaeid limpet, Patelloida latistrigata, and its interaction with barnacles. Oecologia 52:85-96

> Davis AR (1987) Variation in recruitment of the subtidal colonial ascidian Podoclavella cylindrica (Quoy \& Gaimard): the role of substratum choice and early survival. J Exp Mar Biol Ecol 106:57-71

Davis AR (1996) Association among ascidians: facilitation of recruitment in Pyura spinifera. Mar Biol 126:35-41

Davis AR, Ward DW (1999) Does the large barnacle Austrobalanus imperator (Darwin, 1854) structure benthic invertebrate communities in SE Australia? Proceedings of the 5th International Sponge Symposium, 'Origin \& Outlook'. Mem Qld Mus 44:125-130

Davis AR, Fyfe SK, Turon X, Uriz MJ (2003) Size matters sometimes: wall height and the structure of subtidal benthic invertebrate assemblages in south-eastern Australia and Mediterranean Spain. J Biogeogr 30:1797-1807

> Dayton PK (1975) Experimental evaluation of ecological dominance in a rocky intertidal algal community. Ecol Monogr 45:137-159

$>$ Dean TA (1981) Structural aspects of sessile invertebrates as organizing forces in an estuarine fouling community. J Exp Mar Biol Ecol 53:163-180

Dean TA, Hurd LE (1980) Development in an estuarine fouling community: the influence of early colonists on later arrivals. Oecologia 46:295-301

> Downing JA (1986) Spatial heterogeneity: evolved behaviour or mathematical artefact? Nature 323:255-257

Eckman JE (1983) Hydrodynamic processes affecting benthic recruitment. Limnol Oceanogr 28:241-257

Eriksson BK, Rubach A, Hillebrand H (2006) Biotic habitat complexity controls species diversity and nutrient effects on net biomass production. Ecology 87:246-254

Ferguson AM, Davis AR (2008) Heart of glass: spicule armament and physical defense in temperate reef sponges. Mar Ecol Prog Ser 372:77-86

> Fletcher WJ (1987) Interactions among subtidal Australian sea urchins, gastropods, and algae: effects of experimental removals. Ecol Monogr 57:89-109

> Glasby TM (1998) Estimating spatial variability in developing assemblages of epibiota on subtidal hard substrata. Mar Freshw Res 49:429-437

- Grosberg RK (1981) Competitive ability influences habitat choice in marine invertebrates. Nature 290:700-702

Guichard F, Bourget E (1998) Topographic heterogeneity, hydrodynamics, and benthic community structure: a scale-dependent cascade. Mar Ecol Prog Ser 171:59-70
Hauser A, Attrill MJ, Cotton PA (2006) Effects of habitat complexity on the diversity and abundance of macrofauna colonising artificial kelp holdfasts. Mar Ecol Prog Ser 325: 93-100

Heck KL, Orth RJ (1983) Seagrass habitats: the roles of habitat complexity, competition and predation in structuring associated fish and motile macroinvertebrate assemblages. In: Kennedy VS (ed) Estuarine perspectives. Academic Press, New York, p 449-464

Hill MS, Lopez NA, Young KA (2005) Anti-predator defenses in western North Atlantic sponges with evidence of enhanced defense through interactions between spicules and chemicals. Mar Ecol Prog Ser 291:93-102

> Himmelman JH, Cardinal A, Bourget E (1983) Community development following removal of urchins, Stongylocentrotus droebachiensis, from the rocky subtidal zone of the St. Lawrence Estuary, Eastern Canada. Oecologia 59: $27-39$

- Hixon MA, Brostoff WN (1983) Damselfish as keystone species in reverse: Intermediate disturbance and diversity of reef algae. Science 220:511-513

- Hixon MA, Menge BA (1991) Species diversity: Prey refuges modify the interaction effects of predation and competition. Theor Popul Biol 39:178-200

Jeffries MJ, Lawton JH (1984) Enemy free space and the structure of ecological communities. Biol J Linn Soc 23: 269-286

Karlson R (1978) Predation and space utilization patterns in a marine epifaunal community. J Exp Mar Biol Ecol 31: 225-239

Kay AM, Butler AJ (1983) 'Stability' of the fouling communities on the pilings of two piers in South Australia. Oecologia 56:70-78

Kay AM, Keough MJ (1981) Occupation of patches in the epifaunal communities on pier pilings and the bivalve Pinna bicolor at Edithburgh, South Australia. Oecologia 48: 123-130

Keough MJ, Downes BJ (1982) Recruitment of marine invertebrates: the role of active larval choices and early mortality. Oecologia 54:348-352

Kerfoot WC, Sih A (1987) Predation: direct and indirect impacts on aquatic communities. University Press of New England, Hanover, NH

Lawrence JM (1975) On the relationships between marine plants and sea urchins. Oceanogr Mar Biol Annu Rev 13: 213-286

Lawton JH (1983) Plant architecture and the diversity of phytophagous insects. Annu Rev Entomol 28:23-39

Littler MM, Martz DR, Littler DS (1983) Effects of recurrent sand deposition on rocky intertidal organisms: importance of substrate heterogeneity in a fluctuating environment. Mar Ecol Prog Ser 11:129-139

Littler MM, Taylor PR, Littler DS (1986) Plant defense associations in the marine environment. Coral Reefs 5:63-71

> MacArthur RH, MacArthur JW (1961) On bird species diversity. Ecology 42:594-598

McCoy ED, Bell SS (1991) Habitat structure: the evolution and diversification of a complex topic. In: Bell SS, McCoy ED, Mushinsky HR (eds) Habitat structure: the physical arrangement of objects in space. Chapman \& Hall, London, p 3-27

> Menge BA, Lubchenco J (1981) Community organization in temperate and tropical rocky intertidal habitats: prey refuges in relation to consumer pressure gradients. Ecol Monogr 51:429-450

> Russ GR (1980) Effects of predation by fishes, competition, and structural complexity of the substratum on the estab- 
lishment of a marine epifaunal community. J Exp Mar Biol Ecol 42:55-69

Sammarco PW (1980) Diadema and its relationship to coral spat mortality: grazing, competition, and biological disturbance. J Exp Mar Biol Ecol 45:245-272

Sebens KP (1985) Community ecology of vertical walls in the Gulf of Maine, USA: small scale processes and alternative community states. In: Moore PG, Seed R (eds) The ecology of rocky coasts. Columbia University Press, New York, p 346-371

Sebens KP (1986) Spatial relationships among encrusting marine organisms in the New England subtidal zone. Ecol Monogr 56:73-96

Sebens KP (1991) Habitat structure and community dynamics in marine benthic systems. In: Bell SS, McCoy ED, Mushinsky HR (eds) Habitat structure: the physical arrangement of objects in space. Chapman \& Hall, London, p 211-234

Smith F, Witman JD (1999) Species diversity in subtidal landscapes: maintenance by physical processes and larval recruitment. Ecology 80:51-69

Talman SG, Norkko A, Thrush SF, Hewitt JE (2004) Habitat structure and survival of juvenile scallops Pecten novaezelandiae: comparing predation in habitats with varying complexity. Mar Ecol Prog Ser 269:197-207

Underwood AJ, Denley EJ (1984) Paradigms, explanations, and generalizations in models for the structure of intertidal communities on rocky shores. In: Strong DR Jr, Simberloff D, Abele LG, Thistle AB (eds) Ecological communities: conceptual issues and the evidence. Princeton University Press, Princeton, NJ, p 151-180

Editorial responsibility: Richard Osman,

Edgewater, Maryland, USA
Underwood AJ, Denley EJ, Moran MJ (1983) Experimental analyses of the structure and dynamics of mid-shore rocky intertidal communities in New South Wales. Oecologia $56: 202-219$

Vance RR (1979) Effects of grazing by the sea urchin, Centrostephanus coronatus, on prey community composition. Ecology 60:537-546

Walters LJ (1992) Post-settlement success of the arborescent bryozoan Bugula neritina (L.): the importance of structural complexity. J Exp Mar Biol Ecol 164:55-71

Walters LJ, Wethey DS (1991) Settlement, refuges, and adult body form in colonial marine invertebrates: a field experiment. Biol Bull 180:112-118

Walters LJ, Miron G, Bourget E (1999) Endoscopic observations of invertebrate larval substratum exploration and settlement. Mar Ecol Prog Ser 182:95-108

Williamson MH, Lawton JH (1991) Fractal geometry of ecological habitats. In: Bell SS, McCoy ED, Mushinsky HR (eds) Habitat structure: the physical arrangement of objects in space. Chapman \& Hall, London, p 69-86

Witman JD (1985) Refuges, biological disturbance, and rocky subtidal community structure in New England. Ecol Monogr 55:421-445

Woodin SA (1981) Disturbance and community structure in a shallow water sand flat. Ecology 62:1052-1066

Wright JT, Benkendorff K, Davis AR (1997) Habitat associated differences in temperate sponge assemblages: the importance of chemical defence. J Exp Mar Biol Ecol 213:199-213

Young CM, Chia FS (1981) Laboratory evidence for delay of larval settlement in response to a dominant competitor. Int J Invertebr Reprod 3:221-226

Submitted: March 14, 2008; Accepted: December 19, 2008 Proofs received from author(s): March 27, 2009 